\title{
Erratum to: Evaluation of locked nucleic acids for signal enhancement of oligonucleotide probes for microalgae immobilised on solid surfaces
}

\author{
Sonja Diercks • Christine Gescher • Katja Metfies •
}

Linda K. Medlin

Published online: 15 October 2010

(C) Springer Science+Business Media B.V. 2010

Erratum to: J Appl Phycol

DOI 10.1007/s10811-008-9399-0

Unfortunately, Prof. Linda K. Medlin's affiliation was incorrect and should appear as shown below.

The online version of the original article can be found at http://dx.doi. org/10.1007/s10811-008-9399-0.

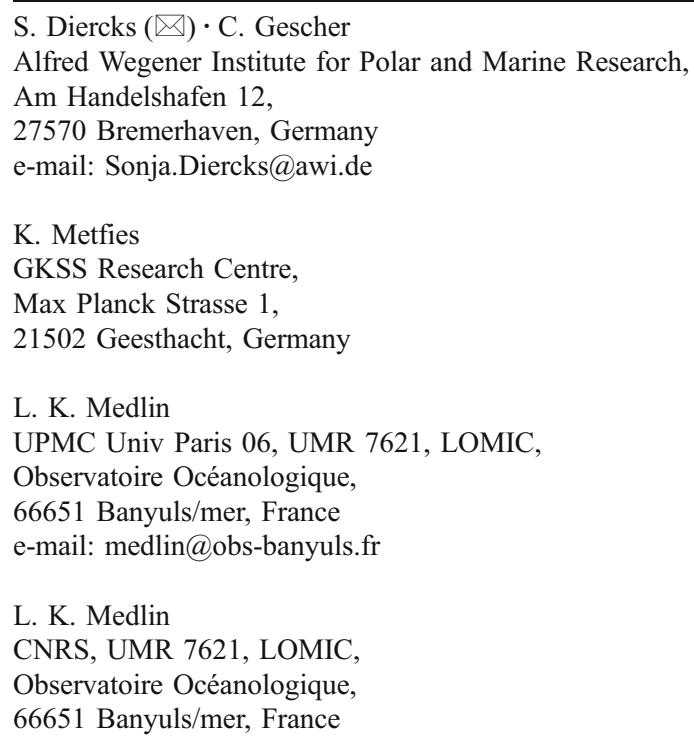

